\title{
Chirping for Large-Scale Maritime Archaeological Survey: A Strategy Developed from a Practical Experience-Based Approach
}

\author{
Ole Grøn ${ }^{1}$ and Lars Ole Boldreel ${ }^{2}$ \\ ${ }^{1}$ Strandingsmuseet St. George, Vesterhavsgade 1E, Thorsminde, 6990 Ulfborg, Denmark \\ ${ }^{2}$ Department of Geosciences and Natural Resource Management, Section of Geology, University of Copenhagen, \\ Øster Voldgade 10, 1350 Copenhagen K, Denmark
}

Correspondence should be addressed to Ole Grøn; olegron111@gmail.com

Received 7 August 2013; Accepted 10 December 2013; Published 29 January 2014

Academic Editor: Vega Pérez-Gracia

Copyright (C) 2014 O. Grøn and L. O. Boldreel. This is an open access article distributed under the Creative Commons Attribution License, which permits unrestricted use, distribution, and reproduction in any medium, provided the original work is properly cited.

\begin{abstract}
Archaeological wrecks exposed on the sea floor are mapped using side-scan and multibeam techniques, whereas the detection of submerged archaeological sites, such as Stone Age settlements, and wrecks, partially or wholly embedded in sea-floor sediments, requires the application of high-resolution subbottom profilers. This paper presents a strategy for cost-effective, large-scale mapping of previously undetected sediment-embedded sites and wrecks based on subbottom profiling with chirp systems. The mapping strategy described includes (a) definition of line spacing depending on the target; (b) interactive surveying, for example, immediate detailed investigation of potential archaeological anomalies on detection with a denser pattern of subbottom survey lines; (c) onboard interpretation during data acquisition; (d) recognition of nongeological anomalies. Consequently, this strategy differs from those employed in several detailed studies of known wreck sites and from the way in which geologists map the sea floor and the geological column beneath it. The strategy has been developed on the basis of extensive practical experience gained during the use of an off-the-shelf 2D chirp system and, given the present state of this technology, it appears well suited to large-scale maritime archaeological mapping.
\end{abstract}

\section{Introduction}

1.1. Background. From 1993 to 1996, a project at the National Museum of Denmark's Centre for Maritime Archaeology, funded by the Danish National Research Foundation, provided the opportunity to begin development of an approach to large-scale mapping and identification of archaeological anomalies embedded in sea-floor sediments. Side-scan and multibeam systems are suited exclusively to the detection of anomalies visible as bathymetrical or microbathymetrical features on the sea floor. They cannot detect anomalies located in sediments below this level. In contrast, subbottom profilers are able, on the basis of vertical profiles, to provide high-resolution information on archaeological features on the sea floor and those totally or partially embedded within the sediments beneath it. Since 1993, chirp subbottom profilers have naturally become the technological mainstay in the development of methods for locating "thin" elements, or elements of restricted size, submerged in sea-floor sediments [1-5]. During this project it was seen as essential to develop a practically applicable strategy for large-scale mapping of sediment-embedded archaeological anomalies, based on off-the-shelf technology, which could readily be replicated by others. Furthermore, because a large part of Denmark's submerged cultural heritage is located in shallow water (zero to a few metres of depth), it was essential that the seismic system employed could be used with acceptable results in water as shallow as $0.5 \mathrm{~m}$. The aim of this paper is, through the presentation of a number of case studies, to demonstrate a cost-effective strategy for the large-scale mapping of submerged archaeological elements embedded in sea-floor sediments. It can also be useful to supplement surveys of larger objects, such as wrecks, with other types of subbottom profilers (boomers, sparkers, etc.). However, 
in our opinion, chirp systems are still most appropriate for detection of the small-scale archaeological features that are so numerous in our area of operation. Lower frequency systems will not be able to detect many of these features due specifically to their lower frequencies and consequent coarser resolution. In our experience, parametric systems are less suited to distinguishing nongeological anomalies of restricted horizontal extent in the sediments, despite their better distinction of approximately horizontal layers than chirp systems. Therefore, the newer digital chirp systems still form the basis of our archaeological surveys.

With regard to the interpolation of $3 \mathrm{D}$ models on the basis of the recorded $2 \mathrm{D}$ data, we are concerned about the skewing of such models which will result from the many elements encountered that are of restricted horizontal extent, but which extend a significant distance vertically (e.g., poles embedded $3 \mathrm{~m}$ into the sea floor). We therefore restrict the use of such 3D models to popular visualisations.

1.2. The 1993 Project. The first year's work focused on testing various subbottom profilers on known submerged archaeological features embedded in the sea-floor sediments in order to discover how these systems would portray them (Figures 1-3). The results were very promising as the trials demonstrated that it was possible to identify small-scale archaeological features in the profiles. An experience-based approach was chosen in order to improve capability with respect to confirming whether the archaeological features detected were actually present. When interesting features were observed, these were then investigated by divers. In an early phase of the project it became apparent that the analogue Datasonics Chirp II system had a remarkable ability to display the correct orientation/inclination and dimensions of sediment-embedded organic/wooden artefacts down to a thickness/diameter of $8-10 \mathrm{~cm}$ (Figures 2, 3, and 5; [2]). For this reason the modern digital version of this system, the Teledyne Chirp III, is now the authors' preferred instrument for archaeological survey. The instrument produces good results for soft as well as hard sediments, such as sand with a certain fraction of organic content. Pure sand with no organic content represents a problem-as with all shallow highresolution systems. Several other systems including ordinary subbottom profilers produce less blurred features but areaccording to our experience-not able to distinguish lowcontrast archaeological features as good as the Teledyne Chirp III.

During the project, large-scale surveying was carried out at a large number of locations. In the course of this it was discovered that the sediment type differed markedly from place to place, so that it was impossible to predict in advance which sediment type would be present at the various locations. Furthermore, the wooden artefacts investigated varied immensely with respect to their degree of degradation; some apparently retained very little of their original physical elasticity [5]. Consequently, it was impossible to predict how they would interact acoustically with the signals emitted from the chirp used in the survey.

Detailed small-scale acoustic investigations (2D or 3D) of known archaeological features containing wood of known species embedded in a known geological context can, through theoretical considerations of their reflective characteristics, help elucidate aspects of the unexcavated parts of these sites, the degradation of their wooden components, and so forth (e.g., [6-9]). The theoretical literature on the reflection characteristics of wooden artefacts embedded in sediment and at varying stages of degradation focuses on oak and pine, the two most common wood types found in wrecks $[5,6,10]$. Oak is a species with a high resistance to natural degradation and it is therefore not optimal as a basis for general modelling of the reflective characteristics of wood in general. Birch/hazel, willow, elm, beech, and a number of other species of particular relevance in a Stone Age settlement context are "slightly resistant or non-resistant” ([11, Chapter 14(5)] and [12, page 34]). They are therefore much more complicated to deal with theoretically, even in relation to the detailed acoustic investigation of known sites. For the survey methodology developed in this project, it was therefore necessary to rely solely on accumulated interpretational experience, as confirmed by diver-derived data, acquired during the project.

After the first year, the Research Centre for Maritime Archaeology had the opportunity to acquire a Datasonics Chirp II subbottom profiler (sweeping at $2-23 \mathrm{kHz}$ ) in collaboration with GEOMAR (at that time Geomarine Forschungszentrum Kiel, today Helmholtz Centre for Ocean Research Kiel). In this final period of the project, the focus shifted to surveying areas with no previously recorded submerged archaeological features. Two approaches were employed in the selection of these areas. (1) Use was made of place-name evidence indicating the presence of specific types of archaeological features, for instance, names in the coastal zone containing "steg," "stige," "led," and so forth indicating a barrage [13] - this strategy proved quite successful. (2) There was also a focus on areas in the vicinity of known archaeological sites with no recorded finds. This strategy was also very productive $[2,3]$.

All interesting acoustic anomalies were subjected to immediate confirmation or rejection via diver examination, a procedure which proved to be a central element in the development work. As the consequence of the 1993-1996 project, a number of hitherto unknown sites were mapped and new details were recorded relating to numerous already known sites $[2,3]$.

Since 1996, this work has been continued as part of various research projects carried out under the auspices of different institutions and in surveys relating to rescue archaeology. From 2006 onwards, the Benthos/Teledyne Chirp III, the digitised version of the analogue Datasonics Chirp II, was used and in 2009 a Teledyne Chirp III was bought jointly by Langelands Museum and the Department of Geography \& Geology, University of Copenhagen.

\section{General Technical Aspects}

It is important to take account of some technical details if good results are to be obtained from the surveys, which can then further underpin the development of large-scale survey strategies. 


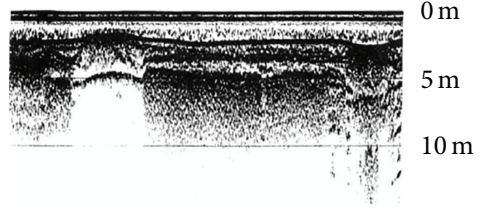

(a)

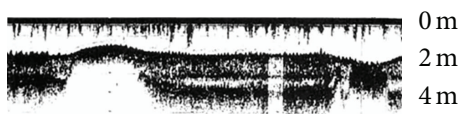

(b)

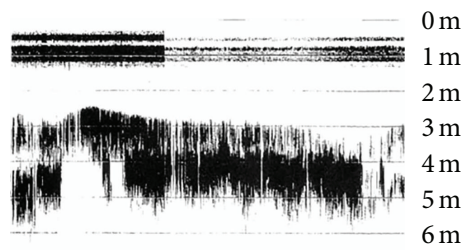

(c)

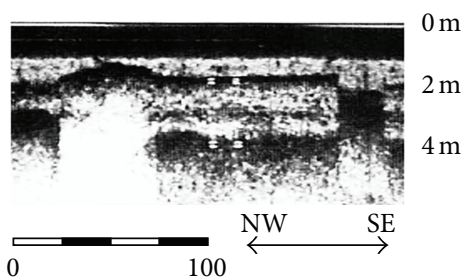

(m)

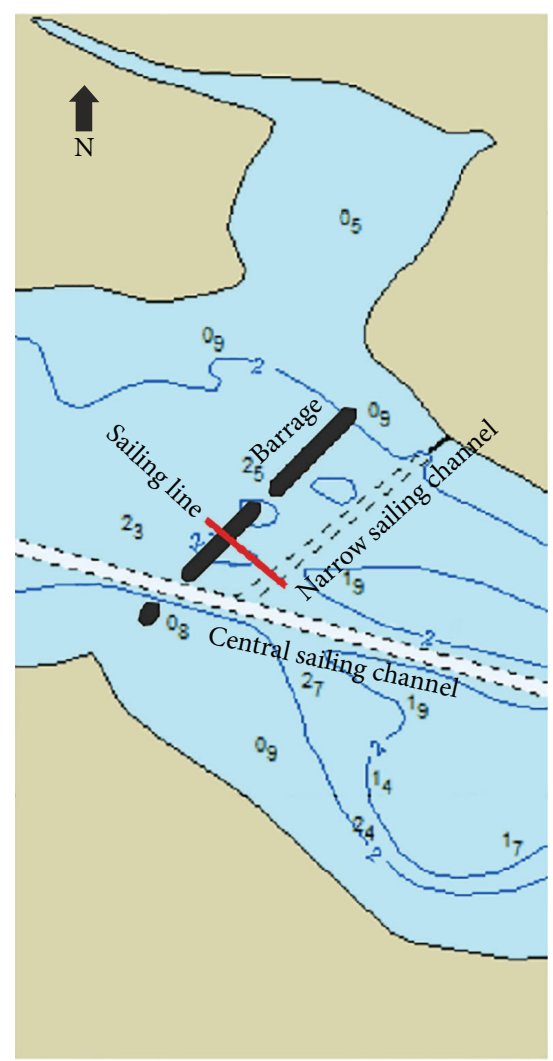

(d)

FIGURE 1: Examples of a NW-SE oriented profile through the “ÆLei” barrage in Haderslev Fjord, recorded using different subbottom profilers and a conventional echo-sounder in order to compare the various systems. In the profiles, the barrage can be seen to the left and the feature to the right is a narrow sailing channel. (a) ELAC sediment echo-sounder (Laz 4700, $30 \mathrm{kHz}$ ). (b) Knudsen sediment echo-sounder (320 M, $33 \mathrm{khz}$ ). (c) Ordinary Furuno echo-sounder (FE-881 MK, $28 \mathrm{kHz}$ ). (d) Analogue Datasonics Chirp II (sweeping the interval 2-22 kHz) equivalent to today's digital Teledyne Chirp III. To the right is a map of the local area and the barrage; the latter dates from the late 4th century AD [4]. The red line represents the sailing line. Graphics based on Grøn [1].

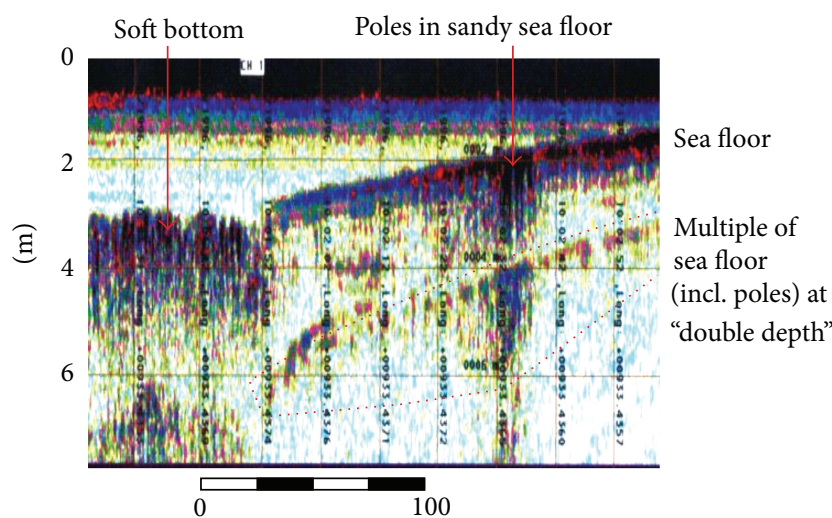

$(\mathrm{m})$

FIGURE 2: Chirp profile through the outer pier of the Viking Age harbour at Haithabu. The poles of this structure are clearly visible in the sandy bottom. The physical recording was carried out by Grøn \& Hoffmann in 1996.
Towing Instrument. If the "fish" (i.e., the chirp transducer) is towed after the boat, small bubbles from the boat's propeller tend to reduce the acoustic signal or block it entirely (e.g., Figure 4, left) [8]. It was therefore necessary to find an alternative way of towing the fish with the vessel. After some experimentation, it was found that the ideal position for the fish, due to its small size and weight $(80 \mathrm{~kg})$, was mounted on one side of the boat and isolated from the vibrations of the hull by a fender (Figure 4, right, upper, and lower).

Positioning. Precise positioning is the backbone of costeffective seismic survey. Work using the Decca Navigator System for positioning in the 1980s, with a precision generally of around $\pm 15-20 \mathrm{~m}$, made it clear that the ability to pinpoint features with submetre precision was a pre-requisite for accurate horizontal plotting of the registered features. Furthermore, significant diving time was also saved when checking the observed anomalies on the sea floor. 


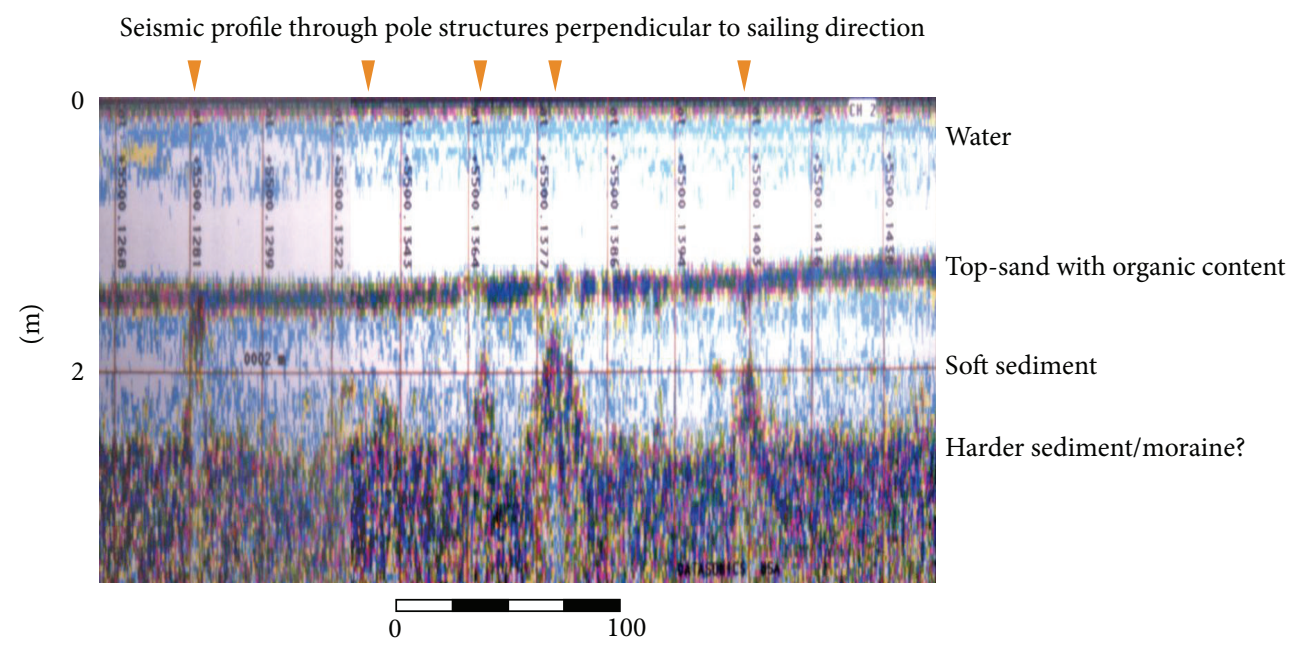

$(\mathrm{m})$

FIGURE 3: Chirp profile through a barrage consisting of a series of lines of poles probably representing repair phases, from the Late Viking Age/Early Middle Ages. The barrage consists of lines of poles that have disintegrated above the sea floor. The barrage also includes a number of poles which probably do not form a straight line; the acoustic signal for the poles therefore varies. The sailing line was perpendicular to the barrage and reveals its various repair phases. Recorded by Grøn.

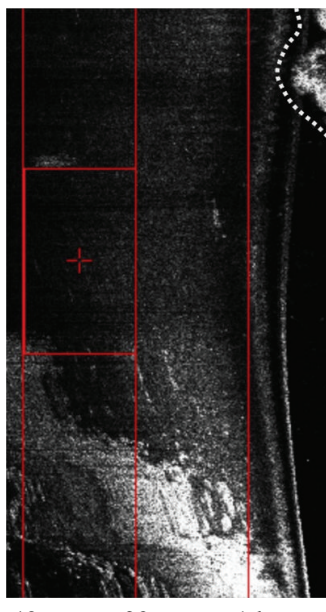

48

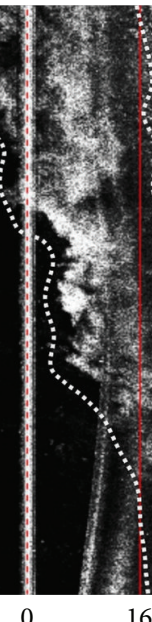

$(\mathrm{m})$
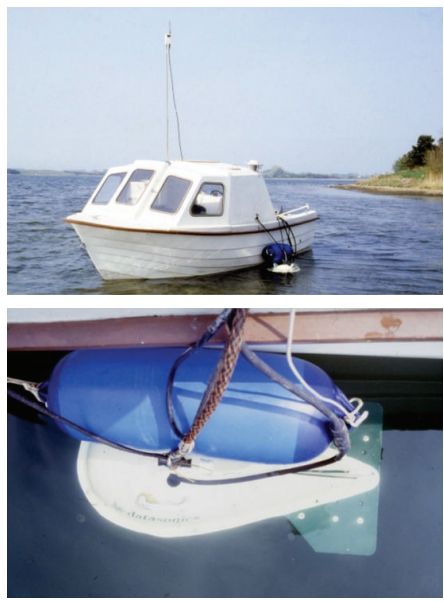

48

FIGURE 4: Left: side-scan of a "cloud" of bubbles, created by the propeller of a fast boat; this blocks the side-scan signal completely. The cloud is outlined with a white dotted line. Recorded by Grøn \& Jolly in 1994, with a small Knudsen side-scanner. Right upper and lower: the fish mounted on the side of the boat to avoid bubbles from the propeller. The fish is isolated from the hull's vibrations by a fender. The DGPS antenna is located on an arm, just above the fish, to avoid having to take account of an offset. The "high" antenna is for communication with the base station on land. Photos by Grøn.

From 1995, the use of an Ashtech DGPS positioning system, with its own separate base station, permitted dynamic positioning with a precision of $\pm 0.3 \mathrm{~m}$ and storage of a position, together with the seismic data, once a second. In turn, this made it possible, with some training, to return to observed anomalies with decimetre precision. Where permanent differential stations for submetre DGPS navigation have been erected, these have proved to be sufficient for most purposes, even though they are not as precise as systems with their own base station.
The attachment of the small fish to the side of the boat allowed the DGPS antenna to be mounted on an arm just above it (Figure 4, right, upper), so that no offset between the boat's position and that of the fish had to be taken into account.

The DGPS coordinates are measured in degrees and decimal minutes and logged on a laptop. The software of the Chirp III (bought in 2009) has been specially designed so that coordinates are logged as UTM values in order to facilitate loading the data, which is in sgy format, onto 


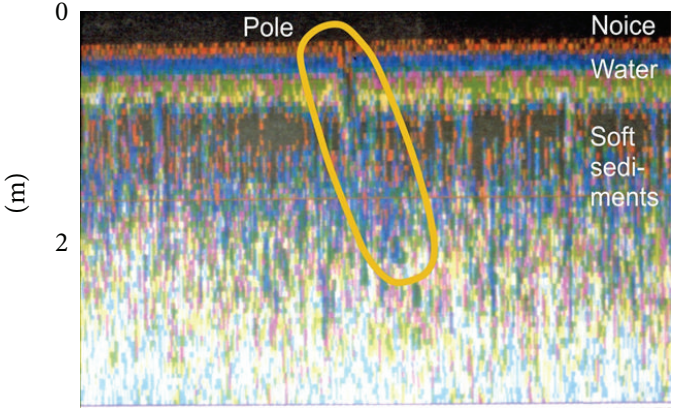

(a)

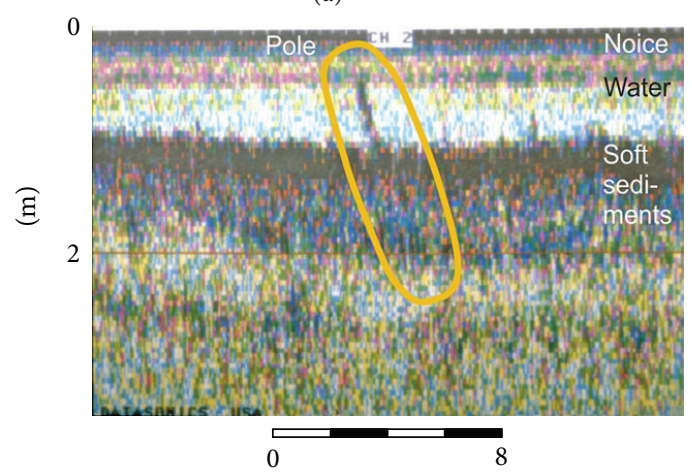

$(\mathrm{m})$

(b)

FIGURE 5: Chirp-recording of a sloping pole, $8 \mathrm{~cm}$ in diameter, visible above and within the sea-floor sediments. Upper image 27 kHz, lower image 8-23 kHz. Recorded by Grøn 1995.

a workstation employing state-of-the-art software used for geophysical seismic interpretation. At the same time, the navigation of the vessel is recorded and, in this manner, two sets of navigation data are stored. This is very useful, should the DGPS system occasionally fail.

Acquisition of High-Resolution Data. High resolution is another important criterion for success in acoustic survey. The chirp system employed provides 2D resolution of the order of 5-10 cm (Figure 5) if the recording speed is reduced to $0.5 \mathrm{~m} / \mathrm{s}$ (= $1 \mathrm{knot}$ ) and the number of pulses (trig-rate) per second is set to a maximum of 8 per second with the analogue instrument and-even better-to 16 per second with the digital version. This differs markedly from geological investigations, where a speed of 4-5 knots is employed.

Our work led us to tune the subbottom profiler, by adjusting gain and cutoff frequencies, in ways which enhanced its display of "discrete" archaeological features. However, this tended to be at the expense of optimal recording of geological features, usually mapped as continuous structures over various horizontal distances. In order to enhance the archaeological features, the following adjustments are important. Since these adjustments are not all mutually independent, the experience-based process of tuning the instrument is difficult to describe. Central factors are the power of the signal emitted, the amplification of the reflected signal (gain), the length and character of the signals (independent of the signal's power), the number of cycles (independent of the signal's power), and so forth. The TVG (time variable gain)-time- (and thereby depth-) dependent signal amplification (and damping) - which can be modelled in detail is important for the continuous process of viewing/analysing the data. For example, it is normally optimal to keep the emitted power as low as possible, but for some sea-floor types it may be necessary to increase this to obtain a good result. The settings are therefore continuously adjusted, according to changing sea-floor conditions. Recording the data with a specific focus on the detection of archaeological features means that the system, in the recording phase, is adjusted continuously to permit these small-scale deviations to be distinguished from the geological layers in an optimal way, but at the expense of optimal recording of the geology. The geological features are, of course, recorded and can normally be interpreted in relation to the archaeological features, but optimal geological recording requires different tuning and a different sailing strategy (see below).

Vessel. In order to be able to operate in shallow water, a $5 \mathrm{~m}$ glass-fibre boat with a small cabin to shield the hardware and prevent reflections from the sun on the display screens was used as working platform. Operations with the chirp system showed that this could produce valid results down to water depths of around $0.5 \mathrm{~m}$ (e.g., Figure 6). At this depth, the boat had to be pulled by a wading diver because the outboard motor could not be used.

A solution involving a small boat of this type is well suited to sheltered Baltic waters, when the weather is not too windy. A small vessel can be easily transported on a trailer, providing a geographical flexibility not possible with a larger and more expensive boat, and operation of the small boat and the Chirp III system only requires two people.

Weather Conditions. In windy weather it is impossible to obtain good recordings, because the signal to noise ratio becomes too poor. This, in turn, means that the data contain a great deal of noise which cannot be removed by later noisereduction processing.

Quite early on, we discovered that our interpretations began to deviate from those of the Geophysical Laboratory, Department of Earth Sciences, at the University of Aarhus, which we were heavily reliant upon for assistance in the early experimental phase of the project. Features we increasingly felt might represent the remains of poles in the sea floor, they insisted were "spikes" reflecting irrelevant noise from the equipment. Diving on these faint "spikes" confirmed, however, that these did quite often represent poles, with diameters as small as $8-10 \mathrm{~cm}$. Almost all of these could be distinguished quite easily in some sediment types, depending on the acoustic impedance. It became apparent that the recording strategy necessary to obtain optimal archaeological results differed so significantly from geological surveying that we were forced to learn the interpretation of archaeological features the hard way-from scratch.

\section{Acquisition Strategies}

The sailing strategy is of crucial importance for the results obtained in subbottom survey. Whereas the lack of precise 


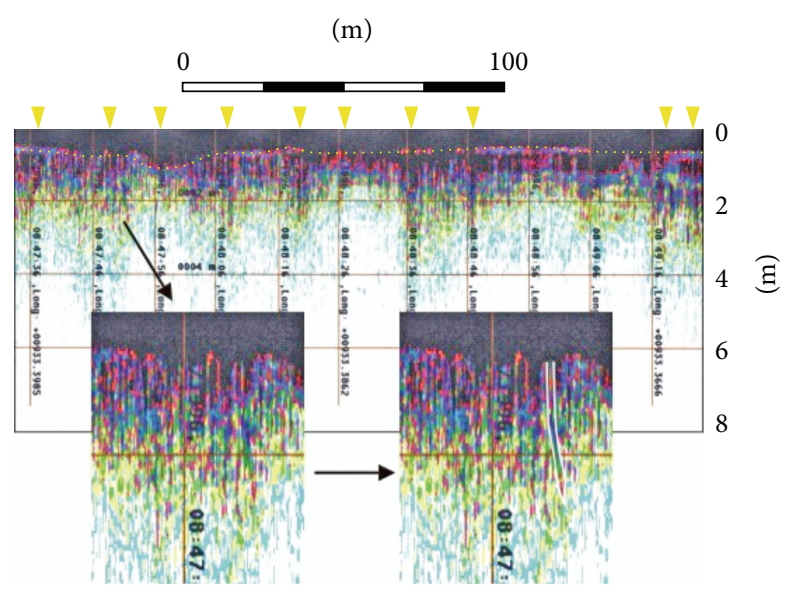

FIGURE 6: Chirp profile in shallow water along the shore of the harbour of the Viking Age settlement of Haithabu. The yellow arrows mark the main concentrations of poles representing the landing piers running approximately perpendicular to the profile. The features observed in the seismic profiles have been verified as linear concentrations of poles. The surface of the sea floor is marked by the broken yellow line. The depths to the right are measured from the bottom of the fish. The actual depths are, in this case, approximately $20 \mathrm{~cm}$ greater. Recorded by Grøn \& Hoffmann in 1996.

satellite positioning previously made it necessary to restrict detailed archaeological subbottom profiling to straight lines controlled by physical fix-points (e.g., [14]), precise dynamic DGPS positioning with submetre precision now allows free movement and thereby optimisation of the sailing strategy as well as direct interaction with the observed potential archaeological features. A dedicated computer screen, displaying a real-time image of the survey lines, makes it possible to ensure reasonable coverage of the sailing lines, for example, a certain maximum distance between them, despite this free movement.

For archaeological purposes, the basic pattern would, as the primary strategy, still comprise straight, parallel, equidistant survey lines, but spaced closer together, depending on the archaeological survey strategy chosen and with the capacity for deviation where necessary to clarify potential archaeological anomalies.

However, it often pays to employ different intervals between the survey lines during the course of an investigation. An initial phase employing intervals of $100-200 \mathrm{~m}$, or an even greater distance, between the survey lines will often make it possible to exclude areas with little potential for preserved prehistoric archaeological features, for example, those which are heavily eroded, or when searching for Stone Age sites of a certain period (e.g., Late Mesolithic, Early Mesolithic, etc.) the zone "outwards" from the coastline of the period will be of little interest.

For detailed survey, we found that the intervals between survey lines should be determined by the size and shape of the features being sought. Barrages located on the sea floor-structures intended to prevent naval attackers from penetrating fjords and other inlets-extend from the one side of a "bottleneck position" to the other and will normally be very readily detected. A few survey lines running in and out of a fjord or inlet, avoiding dredged sailing channels and other recent disturbances, will normally reveal barrage structures. Detailed acoustic recording is then restricted to a zone extending, for example, $100 \mathrm{~m}$ to either side, in order to obtain an acceptable signal contrast. Since barrages often display controlled central access openings [3], it is important to distinguish and record these in detail by way of parallel, transverse survey lines spaced 5-10 $\mathrm{m}$ apart. The optimal orientation of these survey lines is precisely parallel with, and perpendicular to, the structure itself. A large number of transverse profiles are necessary in relation to such structures in order to assess whether they comprise several parallel construction/repair phases, as seen, for example, in the Late Viking Age/Early Medieval barrage at Vordingborg (Figure 3).

When surveying for wrecks embedded in sediments, with no related visible traces on/above the sea floor, the features involved can be quite small. The wrecks themselves can be of the same order as the Haithabu barge which, on excavation, proved to measure only $14.5 \times 2.7 \mathrm{~m}$ [15], and smaller fragments of larger wrecks may also be encountered. An interval of approximately $10 \mathrm{~m}$ between the survey lines should result in detection of the majority of the wrecks, with a grid of the same spacing likely to yield an even better detection rate. Since the orientation of wrecks is unpredictable, no orientation of the survey lines relative to the coastline, dominant currents, and so forth can be recommended. At intervals of $20 \mathrm{~m}$ and above, quite a large proportion of wrecks embedded in sediment may escape detection. Consequently, $10-15 \mathrm{~m}$ should be regarded as the maximum interval between sailing lines for this type of survey.

For Mesolithic Stone Age sites, the features most likely to show up as significant anomalies in a chirp subbottom survey are dwelling pits of approximately 5-10 m in diameter (e.g., $[16,17]$ and $[18$, pages 41-74]). The cultural/archaeological layers themselves may also be observable under some conditions [3]. However, in many situations it must be presumed that they will be difficult to distinguish, as cultural deposits, from the geological deposits within which they are embedded. A subbottom survey in search of Stone Age sites should therefore be carried out with an interval of no more than 5-10 $\mathrm{m}$ between the survey lines.

In 2012, an experiment was carried out to demonstrate the density of sailing lines necessary to locate small archaeological targets using subbottom profilers. This centred on "Lundeborg Wreck 1" approximate the wreck position of which was known in advance. The survey pattern comprised approximately parallel E-W orientated lines supplemented with extra profiles to clarify anomalies that potentially represented the wreck (Figures 7 and 8). This procedure was continued until a recognisable section through the wreck was obtained and its exact position thereby determined.

The wreck, which has been partially excavated and is estimated to measure $15-20 \mathrm{~m}$ by $4-6 \mathrm{~m}$ [19], is recognisable above the sea floor. Because its horizontal extent is equivalent to what might be expected for a Stone Age settlement, 


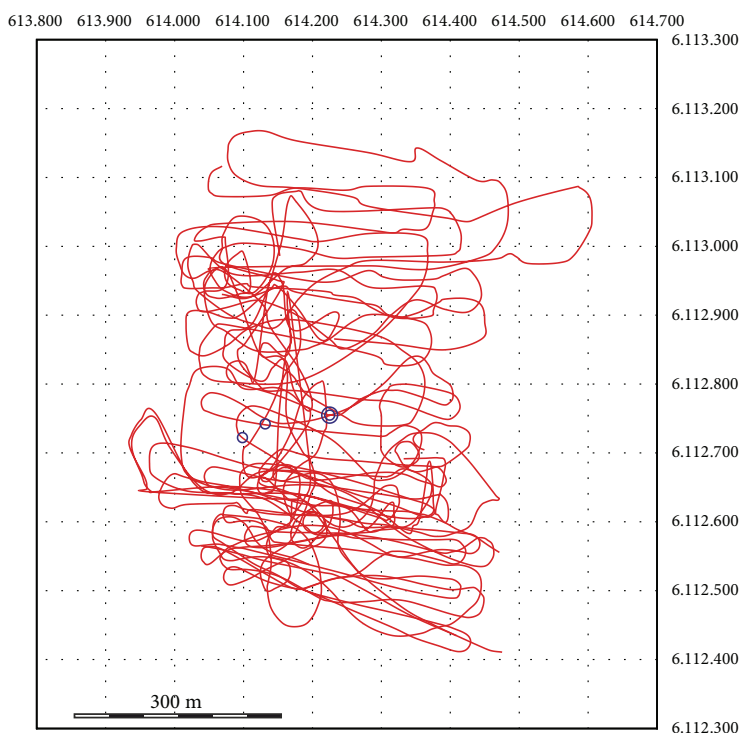

FIgURE 7: Total sailing line from an experimental precision mapping of Wreck 1, Lundeborg (blue double circle) (see Figure 8), for which only an approximate position was known. Two other wreck features were observed (blue single circles); the westernmost is most likely Wreck 2, Lundeborg, which represents one half of another medieval ship; the other may represent the "missing" half of Wreck 2 or a third wreck. The sailing pattern represents approximately 10 hours of sailing time at the location. This illustration has been produced by Grøn and Boldreel.

the exercise gives a good idea of the density of sailing lines necessary to distinguish Stone Age sites embedded in seafloor sediments.

\section{Interactive Sailing}

On-site recognition of small-scale features of nongeological origin, combined with flexible sailing during surveying, facilitates immediate and cost-effective clarification of anomalies which may represent archaeological features.

A prerequisite for the employment of a flexible sailing strategy is that the operator of the subbottom profiler is able to identify potential archaeological features and interact immediately with them to provide further clarification. Such interaction is only possible with newer systems which provide a highly processed screen image close to "real-shape" (e.g., Figures 2, 3, 5, and 6). It would have been impossible with earlier system types which reflected anomalies as "raw" diffraction hyperbola indicating nothing about the shape of the anomalies which caused them $[3,14]$. The high level of immediate processing of the subbottom data presented on the screen, facilitating immediate interpretation, is oftenfor instance, in the case of the Datasonics Chirp II/BenthosTeledyne Chirp III-very good. However, it comes at a cost in that further data processing is often limited to noise reduction, frequency filtering, and migration. Interactive adjustment, which is so crucial in surveying for archaeology, is very difficult to handle from a geophysical processing point of view if the various acquisition parameters are to

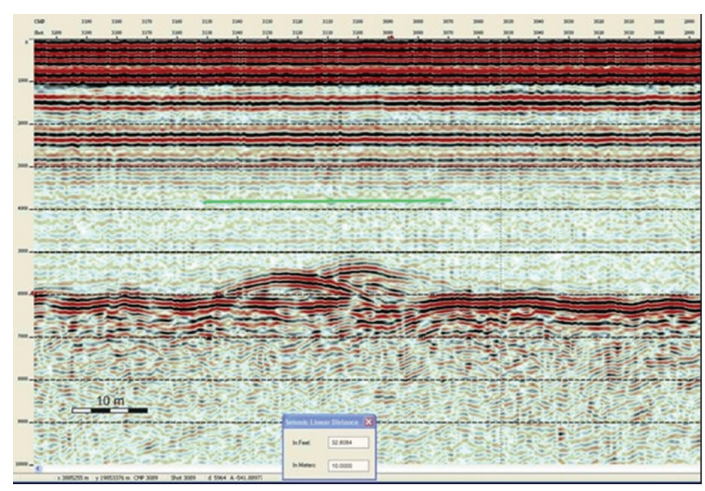

FIGURE 8: Section through Wreck 1, Lundeborg, with visible features both above and below the surface of the sea floor. The wreck is covered by sediment above the base level of the sea floor. Apparently it is possible to distinguish the undisturbed part of this "sediment heap" from the part which was removed during partial excavation of the wreck and then back-filled. The Chirp data were loaded onto a workstation using state-of-the-art interpretation software for geological surveying (GeoGraphix) (2). Recorded by Grøn \& Boldreel in 2012.

be found in the same file. Thus, in order to be able to do postacquisition processing, it is strongly recommended that major parameter-shifts are only carried out when starting the recording of new lines. This will also be an advantage when the data are loaded onto a workstation.

A good example of the effectiveness of this interactive and flexible strategy is the discovery in 1996 of a barge dating from c. AD 1175 (Figure 9) during a survey in Haddeby Noor, the inlet where Haithabu (= Haddeby in modern German) was located $[2,15]$. The wreck, which was totally embedded in the soft sediments of the sea floor, was immediately observed by the chirp operator as the survey vessel passed over it. At this stage, the anomalies merely represented a promising feature which could potentially represent many different types of archaeological feature or natural phenomena. Instead of continuing along the planned survey line (red line in Figure 9) and then afterwards interpreting the recorded data prior to a possible return for further acoustic clarification, we turned the vessel immediately and recorded a number of short profiles at different angles through the anomalies. This meant that (1) after 15-minute work we were able to conclude that the anomaly represented two up to $15-20 \mathrm{~m}$ long and 4-5 m wide features of which the one to the NW was, with 95\% probability, estimated to be a wreck and (2) we could dispense with a later, expensive, return to the anomaly for further acoustic clarification. It should be noted that such features will often, due to deposits formed around them, look somewhat larger than they really are. After recording of the short extra profiles, the recording line which led to the discovery was then resumed.

In comparison, if the objective of the survey had been mapping of the geology of Haddeby Noor, a series of approximately straight, parallel, and equidistant survey lines, 20$30 \mathrm{~m}$ apart, rather than the $10 \mathrm{~m}$ spacing employed, would probably have been sufficient as the inlet's geological features 


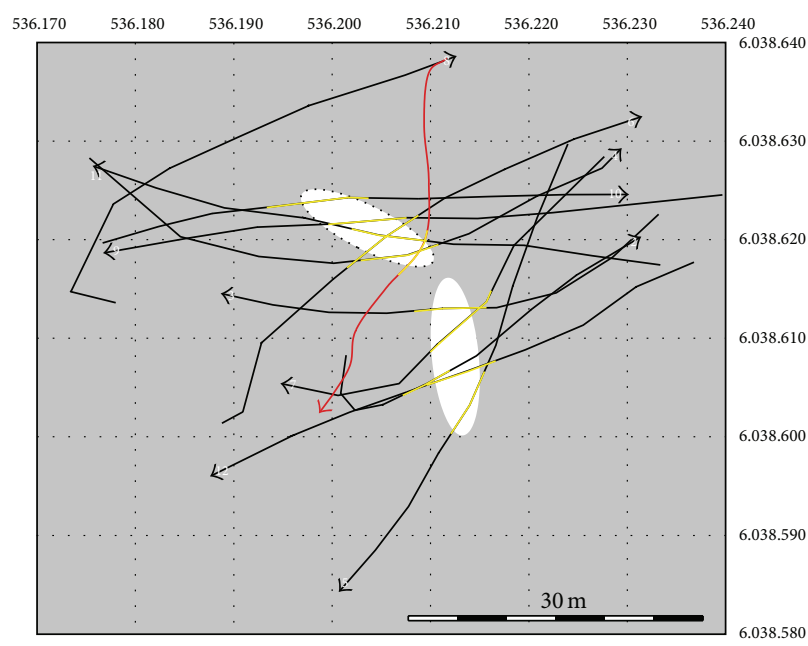

(a)

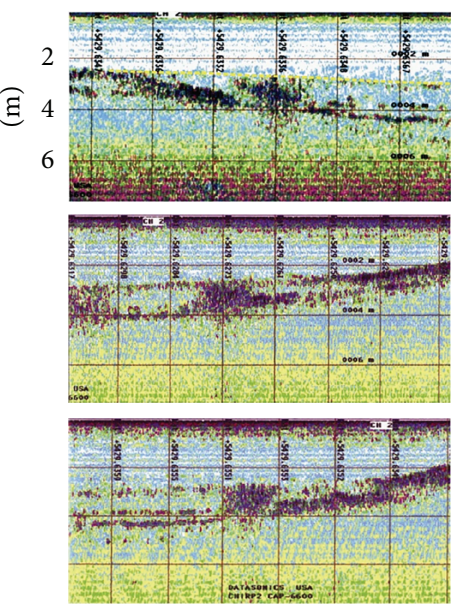

(b)

Figure 9: During seismic survey of Haddeby Noor in 1996 [2], a barge (oval with dotted outline) dated to c. AD 1175 was discovered. First, an anomaly was observed during recording of the red sailing line. A number of supplementary profiles were then immediately recorded (shown as arrowed lines in the map, left) to elucidate the character of the anomaly in detail (sections, right). It was estimated that the first observed anomaly, with $95 \%$ probability, represented a boat/ship. Furthermore, it was concluded that the neighbouring anomaly (white oval) represented a natural phenomenon. With the present level of experience, the probability that the latter actually represents another boat is estimated at about $50 \%$. After the seismic clarification, the red sailing line was resumed. Graphics produced by Grøn.

show very little horizontal variation. A survey velocity considerably greater than the 1 knot employed for archaeology would also have been acceptable. Depending on the sedimentary conditions, perpendicular recording lines could then be added where relevant to make the data better suited as a basis for 3D presentations-or, ultimately, by sailing a grid of survey lines 20-30 $\mathrm{m}$ apart.

One of many other positive examples of the benefits of interactive sailing was the discovery of a Late Viking Age barrage in Kerteminde Fjord in 1996. The survey focussed the narrow fjord located immediately south of the village of "Snekkeled," a place-name indicating the presence of a Viking Age barrage. This location appeared ideal for a barrage across the fjord. However, as we had found nothing by evening, we began to sail east towards our harbour at Munkebo, still in survey mode with the chirp switched on. At a position $1.3 \mathrm{~km}$ east of Snekkeled we observed a massive anomaly, but test-profiles revealed this to be a sewer which had previously carried waste water out into the fjord. A few hundred metres further east, however, we crossed a structure with the typical features of a barrage. A few extra profiles confirmed this and the following day we recorded the feature in detail (Figure 10) [3].

\section{The On-Site Interpretation and Investigation of Archaeological Features}

The key advantage of the type of subbottom survey described here is that immediate interpretation of the seismic data facilitates an interactive approach. A prerequisite for satisfactory results is therefore the involvement of an operator experienced in the interpretation of submerged archaeological anomalies. The difference between features which should, or should not, be classified as "potentially archaeological" often lies in the configuration of the received reflected signals (expressed in the colouring) of a few pixels on images of quite coarse resolution (e.g., Figure 5). Because the highest frequency transmitted by the Teledyne Chirp II is $20 \mathrm{kHz}$, equivalent to a wavelength in water of approximately $7.5 \mathrm{~cm}$, there is a limit to the vertical resolution with which the system can record; with a vertical resolution of half a wavelength this corresponds to approximately $3.7 \mathrm{~cm}$. In modern geophysics, the horizontal resolution typically has a lower limit of about $8 \mathrm{~cm}$. In cases where it is impossible to distinguish between false shadows and reflections on the one hand and actual features on the other, it is a good idea to employ a diving underwater archaeologist for "ground-truthing" in order to become better acquainted with the characteristics of observed anomalies.

Some constructions generate surprising reflections. For example, concentrations of vertical poles/stakes embedded in the sea floor are often not reflected as visible single poles but as "white-out" zones covering the pole areas. The central part of the Kerteminde barrage (Figure 10, upper) displays just such a central vertical "white-out," where the quite narrow pole zone of this barrage could be observed during groundtruthing by divers.

Smaller anomalies and anomalies resembling the many shadows and false echoes are not well suited to automatic or semiautomatic recognition through existing types of patternrecognition systems. Even though some of the larger features 


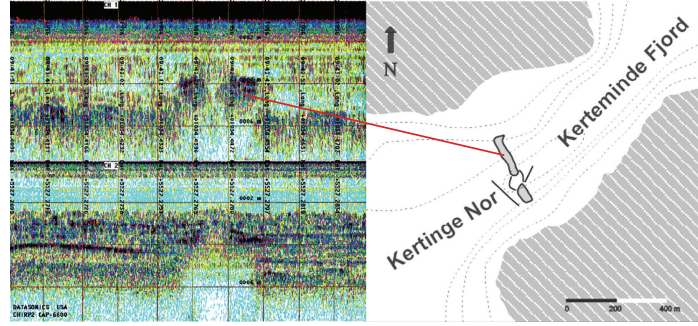

FIgURE 10: The Viking Age barrage discovered in Kerteminde Fjord in 1996 . The barrage appeared as a $70-80 \mathrm{~m}$ broad acoustic anomaly. This consisted mainly of the relatively coarse sediments that had been deposited around the poles of the structure, which in itself was not more than $10 \mathrm{~m}$ across. Graphics produced by Grøn.

do appear more promising from this point of view, it seems that a trained human operator and interpreter will be necessary for successful archaeological subbottom profiling for quite some years to come.

The greater the depth of water above the sea floor is the less detailed the recorded sediment data will be if the chirp is kept at the surface. The distance from the transducer ("fish") to the sea floor should not exceed $10 \mathrm{~m}$ if detailed data are required. In deeper waters, deep-towing of the fish should be employed.

Strategically speaking, there is a gradual transition from large-scale subbottom survey to a level where the subbottom profiling becomes an integrated part of the actual excavation of a specific archaeological feature. Covering an investigation area with a $5 \mathrm{~m}$ grid of survey lines prior to excavation will often provide so much information about the $3 \mathrm{D}$ configuration of the archaeological features that it is possible to focus the subsequent excavation on the zones where the various structural/chronological questions are most likely to find answers, rather than starting at random.

\section{Discussion}

The main aim of this paper is to demonstrate that subbottom profiling directed at producing optimal archaeological results should be carried out differently from surveys with a general geological purpose. For the optimal detection of submerged archaeological features it is necessary to sail slower, use a different sailing strategy with a higher resolution, and tune the instrument differently and interactively-aiming for maximum horizontal and vertical resolution. The operator should be trained in the interpretation of archaeological features and be able to interact with these immediately as they appear. The focus should be on the detection of features that deviate from the geology, instead of on the geology itself.

It is of course a tempting and a cheaper solution to run geological and archaeological subbottom surveys together along straight survey lines, at the 50-200 m intervals which are generally regarded as sufficient for geological purposes which is the practice in development-led surveys. Of course the large-scale landscape information obtained by such surveys is important for the understanding of the submerged prehistoric landscapes and the mapping of archaeological objects such as large wrecks and submerged harbours. It is, however, neither a satisfactory nor a responsible solution when surveying for smaller archaeological features with subbottom profilers. The surprisingly modest number of submerged Stone Age sites located in Danish waters during marine surveys relating to large-scale marine construction projects, such as the building of offshore windmill parks, laying cables and pipe lines, despite the existence of extensive areas with good potential for prehistoric habitation within the areas surveyed, strongly indicates that better survey methodologies are urgently required if we are to manage the submerged cultural heritage appropriately and responsibly. It has been demonstrated that the Teledyne Chirp III is able to distinguish Stone Age cultural layers as hard reflectors. However the system does not allow a distinction between cultural layers and natural hard layers which means that this ability will not be very useful unless features such as pits/dwelling pits and stake/post holes can be used to identify submerged settlement areas or before it can be combined with a method for geoacoustic characterisation of cultural layers based on worked flints, charcoal particles, and so forth $[3,20,21]$.

In relation to the survey strategy described here, which relies on on-site interactivity, the use of $3 \mathrm{D}$ chirp systems (e.g., [7, 9, 22]) is, as yet, restricted by the lack of a user interface which allows immediate recognition of potential archaeological anomalies on-site. Furthermore the "fusion" of reflected signals emitted and received by several chirp units into a $3 \mathrm{D}$ image is thought to give a less precise result than data recorded by single units. The problem inferred here is that $3 \mathrm{D}$ systems may be less sensitive to the faint signal variations which can, at times, signify archaeological features. For example, the fact that the SEAMAP-3D system, which was employed offshore from Haithabu in Haddeby Noor in 2007, did not distinguish the numerous landing piers we had mapped with an old analogue Chirp II in 1996 and furthermore verified by direct nondestructive groundtruthing could be a result of this resolution problem [23].

In areas deeper and more dynamic than the Baltic, where it can be difficult to improvise transverse profiles through an interesting newly observed anomaly on-site, the immediate solution would be to transfer the fine manoeuvring of the chirp system to a remotely operated vehicle-ROV-which can move at an appropriate distance above the sea floor. This would allow for the necessary interactivity. Autonomous underwater vehicles-AUVs-at the present state of their technology lack the essential interactivity parameter.

An indirect site-detection methodology for submerged Stone Age sites has recently gained administrative acceptance in Danish maritime cultural heritage management. Multibeam data are used to create a topographical model ("bathymetry") of the sea floor and potential settlement areas are identified on this basis. This type of predictive modelling is likely to indicate categories of potential settlement locations dictated by significant topographical configurations (e.g., [24]). However, its inability to account for potential settlement locations related to fluctuating resource patterns in the landscape, as well as resource concentrations created artificially by human hunter-gatherers (a perspective which 
today must clearly be accepted as a part of the hunter-gatherer package), makes it necessary to supplement this rather basic modelling approach with direct detection over large areas [25].

It is not that the implemented prediction modellingbased approach does not locate sites. The problem is that, according to our improved understanding of hunter-gatherer resource manipulation, this approach is only able to locate some types of topographically determined sites. It does not indicate the positions of other site types that may be just as, or even more, important. The quality of predictive modelling methodologies could be improved somewhat through the incorporation of a large body of high-resolution spatiotemporal environmental data. This would be an extremely expensive exercise and it would still most probably not enable these methodologies to deal with the significant and rapid resource fluctuations typical of ecosystems, not least as a consequence of the restricted precision of our dating methodologies [25].

Due to the problems inherent in indirect site location methods it is important to develop cost-effective direct detection methods for the mapping of submerged archaeological features. Improvements to existing acoustic techniques, such as those discussed above in relation to subbottom profiling, together with the development of new survey techniques, appear to be logical areas on which to focus in the development of up-to-date management strategies appropriate to the submerged cultural heritage $[3,20]$.

\section{Conflict of Interests}

The authors declare that there is no conflict of interests regarding the publication of this paper.

\section{Acknowledgments}

David Simpson, Jostein Gundersen, and Jørgen Dencker are all thanked for comments and suggestions relating to various versions of this paper. Anne Bloch and David Earle Robinson are likewise thanked in relation to revision of the English. Any errors in the text are the sole responsibility of the authors. Thanks are also due to Landmark for issuing a University Grant to the University of Copenhagen for seismic interpretation.

\section{References}

[1] O. Grøn, "Use of sediment echo-sounding for location of archaeological sites under water," Archaeology Newsletter from Roskilde, Denmark, no. 4, 1995.

[2] O. Grøn, G. Hoffmann, H. Brunn, and K. Schietzel, "The use of acoustic high resolution sub-bottom profilers for geoarchaeological survey. Results from jungshoved, kerteminde firth and haitbabu/hedeby," in Studien zur Archaologie des Ostseeraumes. Von der Eisenzeit zum Mittelalter. Festschrift fur Michael Müller-Wille, Anke Wesse, Ed., pp. 151-160, 1998.

[3] O. Grøn, A. Nørgård Jørgensen, and G. Hoffmann, "Marine archaeological survey by high-resolution sub-bottom profilers," Norsk Sjøfartsmuseums Årbok, pp. 115-144, 2007.
[4] A. N. Jørgensen and O. Grøn, "Investigations within the Coastal Defence Project, 1993-1996," Archaeology Newsletter from Roskilde, Denmark, no. 9, 1997.

[5] R. Quinn, J. M. Bull, and J. K. Dix, "Imaging wooden artefacts using chirp sources," Archaeological Prospection, vol. 4, pp. 2535, 1997.

[6] S. H. L. Arnott, J. K. Dix, A. I. Best, and D. J. Gregory, "Imaging of buried archaeological materials: the reflection properties of archaeological wood," Marine Geophysical Researches, vol. 26, no. 2-4, pp. 135-144, 2005.

[7] M. Gutowski, J. M. Bull, J. K. Dix et al., "3D high-resolution acoustic imaging of the sub-seabed," Applied Acoustics, vol. 69, no. 3, pp. 262-271, 2008.

[8] R. M. K. Plets, J. K. Dix, and A. I. Best, "Mapping of the buried yarmouth roads wreck, Isle of Wight, UK, using a chirp subbottom profiler," International Journal of Nautical Archaeology, vol. 37, no. 2, pp. 360-373, 2008.

[9] R. M. K. Plets, J. K. Dix, J. R. Adams et al., "The use of a highresolution 3D Chirp sub-bottom profiler for the reconstruction of the shallow water archaeological site of the Grace Dieu (1439), River Hamble, UK," Journal of Archaeological Science, vol. 36, no. 2, pp. 408-418, 2009.

[10] J. M. Bull, R. Quinn, and J. K. Dix, "Reflection coefficient calculation from marine high resolution seismic reflection (chirp) data and application to an archaeological case study," Marine Geophysical Researches, vol. 20, no. 1, pp. 1-11, 1998.

[11] C. A. Clausen, "Biodeterioration of wood," in Wood Handbook: Wood as an Engineering Material, R. Bergman and S. Bowe, Eds., Tech. Rep. FPL-GTR-113, Department of Agriculture, Forest Service, Forest Products Laboratory, Madison, Wis, USA, 2010.

[12] T. C. Scheffer and J. J. Morell, "Natural durability of wood: a worldwide checklist of species," Tech. Rep. 22, College of Forestry/Oregon Forest Research Laboratory (FRL), Forest Research Laboratory, Research Contribution, 1998.

[13] B. Holmberg, "Stednavne som historisk kilde" in Atlas Over Fyns Kyst I Jernalder, VIkIngetId og MIddelalder, O. CrumlinPedersen, E. Porsmose, and H. Thrane, Eds., pp. 53-58, Odense Universitetsforlag, 1996.

[14] H. Stümpel and B. Borth-Hoffmann, "Seismische Untersuchungen im Hafen von Haithabu," in Archäometrische Untersuchungen. Berichte Über die Ausgrabungen in Haithabu, K. Schietzel, Ed., pp. 9-28, Karl Wacholtz, Neumünster, Germany, 1984.

[15] C. V. Carnap-Bornheim, S. Hartz, H. J. Kühn, and O. Nakoinz, "Wrack 4 von haithabu," Nachrichtenblatt Arbeitskreis Unterwasserarchäologie, vol. 9, pp. 95-98, 2002.

[16] O. Grøn, "Mesolithic dwelling places in south Scandinavia: their definition and social interpretation," Antiquity, vol. 77, no. 298, pp. 685-708, 2003.

[17] L. Larsson, "Acontribution to the knowledge of mesolithic huts in southern scandinavia," 1973-1974, MLUHM, 1975.

[18] J. Skaarup and O. Grøn, Møllegabet II. A Submerged Mesolithic Settlement in Southern Denmark, BAR International, British Archaeological Reports, Oxford, UK, 2004.

[19] J. Skaarup, "Tiles and coastal trade. a contribution to the economic life of south-east funen and langeland during the renaissance," Journal of Danish Archaeology, vol. 3, pp. 177-186, 1984.

[20] J.-P. Hermand, O. Grøn, M. Asch, and Q. Ren, "Modelling flint acoustics for detection of submerged stone age sites," in Proceedings of the MTS/IEEE Kona Conference (OCEANS' '11), September 2011. 
[21] J. P. Hermand and R. Tayong, "Geoacoustic characterization of stone age cultural layers: preliminary FE modelling," in Proceedings of the MTS/IEEE, OCEANS-Bergen, pp. 1-6, 2013.

[22] J. M. Bull, M. Gutowski, J. K. Dix et al., "Design of a 3D chirp sub-bottom imaging system," Marine Geophysical Researches, vol. 26, no. 2-4, pp. 157-169, 2005.

[23] C. Mueller, S. Woelz, and S. Kalmring, "High-resolution 3D marine seismic investigation of hedeby Harbour, Germany," The International Journal of Nautical Archaeology, vol. 42, no. 2, 2013.

[24] A. Fischer, "People and the sea-settlement and fishing along the mesolithic coasts," in Danish Storebaelt Since the Ice Age: Man, Sea and Forest, L. Pedersen, A. Fischer, and B. Aaby, Eds., pp. 63-77, . A/S Storebaelt Fixed Link, Copenhagen, Denmark, 1997.

[25] O. Grøn, "Our grandfather sent the elk—some problems for hunter-gatherer predictive modelling," Quartär, vol. 59, pp. 175$188,2012$. 

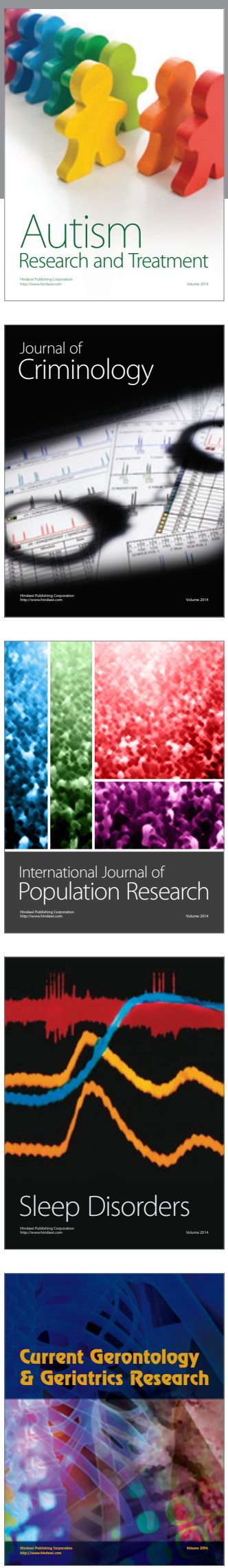
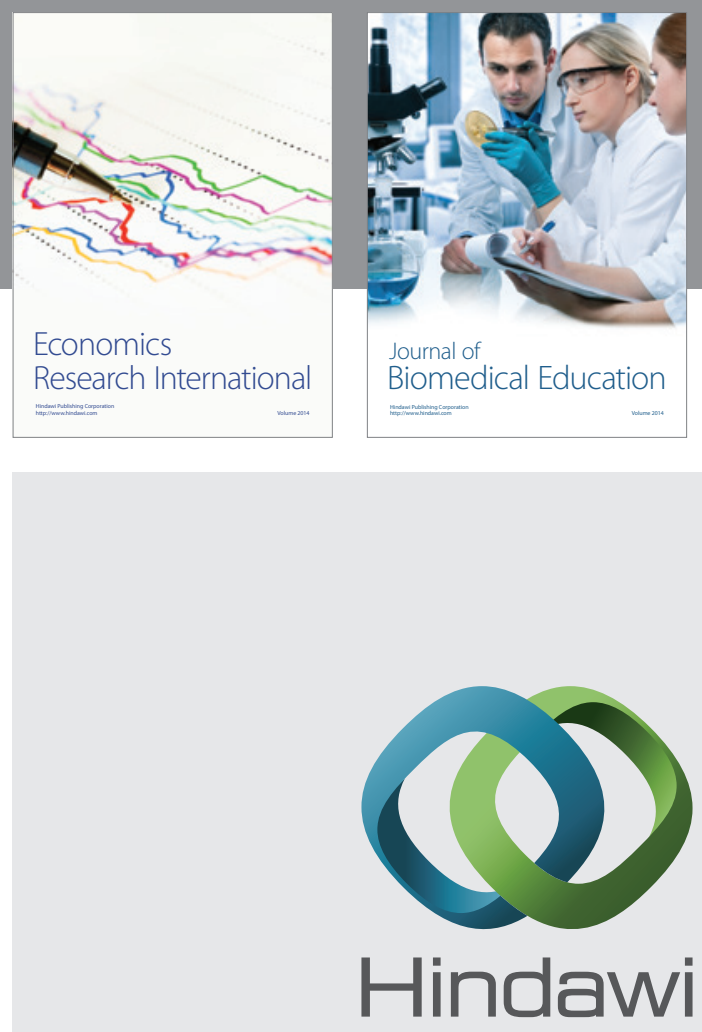

Submit your manuscripts at

http://www.hindawi.com
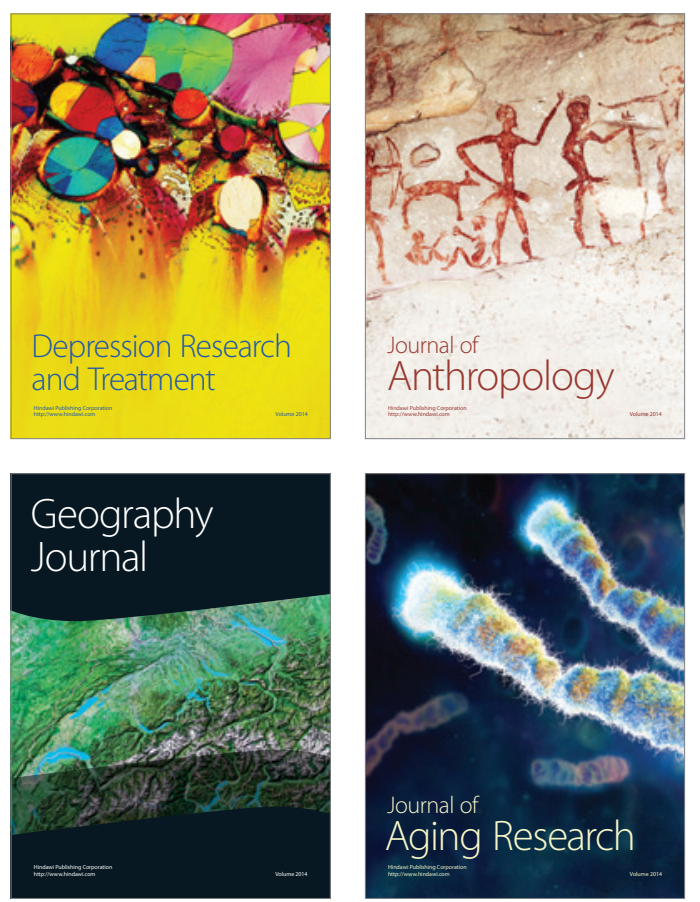
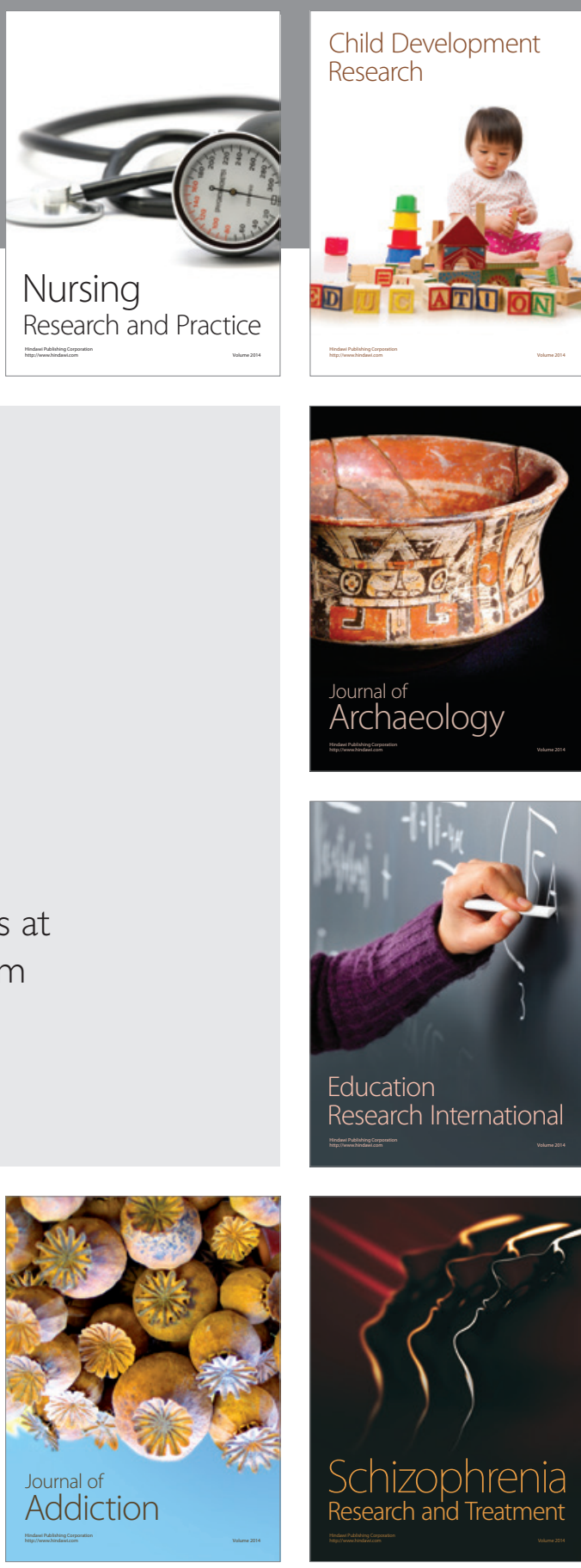

(D)
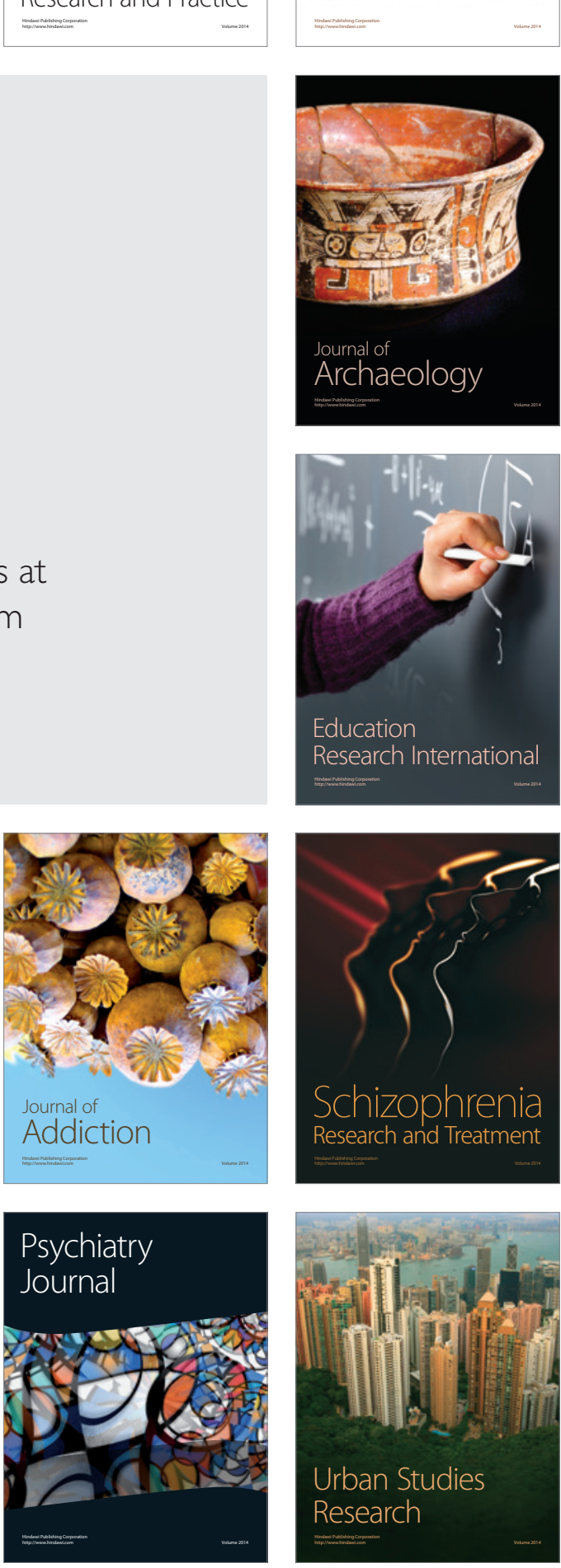